\title{
ENSINO DE GEOGRAFIA: CONTRIBUIÇÃO DA JOGOS DIDÁTICOS NA COMPREENSÃO DA CARTOGRAFIA.
}

\section{GEOGRAPHY TEACHING: CONTRIBUTION FROM THE EDUCATIONAL GAMES TO THE COMPREHENSION OF CARTOGRAPHY}

Vidal Gabriel da Silva Carvalho'; João Rafael da Silva Carvalho²; Vitor Gabriel Moura Firmino da Silva ${ }^{3}$, Rafael Manoel de Souza Silva ${ }^{4}$; Mádson Francisco da Silva ${ }^{5}$

\section{INTRODUÇÃO}

Durante o processo de ensino, muitos professores sentem dificuldades para diversificar suas estratégias didáticas quando os conteúdos de geografia são abordados. Nesse sentido, o educador se ver numa condição que requer inovação pedagógica para fomentar novos saberes no âmbito da geografia de forma mais dinâmica e significativa a sua sala de aula, tornando assim, a aula atraente aos seus estudantes.

Os jogos e brincadeiras proporcionam os alunos, a aprender de forma prazerosa, os alunos interagem uns com os outros desenvolvendo suas habilidades, ampliando seu intelecto sem ter a "obrigação" de aprender; tudo acontece de forma espontânea fazendo com que ele seja mais ativo em sala. Através dos jogos o aluno passa a entender e desenvolver a imaginação de modo que eles possam sonhar, sentir, decidir, se aventurar e agir, recriando o tempo e o espaço da brincadeira, colocando toda sua imaginação em ação. Os autores Smole, Diniz, Cândido (2007, p.13), afirmam que "o jogo é uma das formas mais adequadas para que a socialização ocorra e permita aprendizagens"

Desse modo, justifica-se a existência desse estudo diante da necessidade de valorizar a utilização dos jogos didáticos no ensino de geografia, como um instrumento facilitador para a efetivação dos saberes na área mencionada, e assim identificar a importância dos jogos didáticos nas aulas de geografia e registrar às especificidades do conhecimento geográfico emergido dos jogos didáticos.

\section{FUNDAMENTAÇÃO TEÓRICA}

O ensino da geografia é amplo e um dos elementos fundamentais para contribuir na compressão da geografia é por meio da cartográfica. E, o ensino desta tem como objetivo criar condições e meios para que o aluno compreenda as dimensões do espaço onde ele está

\footnotetext{
${ }^{1}$ Licenciatura em Geografia, Universidade de Pernambuco, joaorafael1557@gmail.com

${ }^{2}$ Licenciatura em Geografia, Universidade de Pernambuco, vidallcarvalho@gmail.com

${ }^{3}$ Licenciatura em Geografia, Universidade de Pernambuco, vitgabriel@gmail.com

${ }^{4}$ Licenciatura em Geografia, Universidade de Pernambuco, rafaelmanoel2011@ hotmail.com

${ }^{5}$ Mestre em Educação, Universidade de Pernambuco, mamadson123@hotmail.comm
} 
inserido, fazendo com que as crianças e os adolescentes desenvolvam informações dada pelo professor e insira ao seu dia-dia. Partindo desse viés, Castellar e Vilhena (2010), comenta que:

O letramento geográfico é, portanto, o ponto de partida para estimular o raciocínio espacial do aluno, articulando a realidade com os objetos e os fenômenos que querem representar, na medida em que se estrutura a partir das noções cartográficas. (CASTELLAR e VILHENA, 2010, p. 25).

Tendo isso pode-se dizer, que o uso de jogos favorece a participação ativa dos alunos em atividades escolares, sendo uma ferramenta eficaz no combate ao baixo rendimento escolar a falta de interesse dos estudantes no processo educativo, levando em conta o seu desempenho com jogos referentes aos conteúdos, sendo assim o educador desenvolve meios de repassar as informações necessárias, analisando constantemente se está havendo compreensão por partes dos alunos.

A produção dos jogos didáticos compõe a oficina pedagógica, um importante instrumento que torna as aulas mais dinâmicas ao mobilizar a participação dos alunos e ao mesmo tempo romper o ensino tradicional baseado apenas na assimilação de conteúdos já pronto. Silva e Muniz (2012, p 65) destacam que "os jogos representam uma ferramenta instigante para o ensino da Geografia, pois têm um caráter desafiador, permitem desenvolver a capacidade ativa de raciocínio e trabalhar a vontade de autos superação".

Corrobora com esse pensamento Celso Antunes (2003) afirma que:

A qualidade do ensino com jogos depende da maneira como as regras são colocadas
e executada, e é sobretudo pelo papel do educador que o jogo pode se tornar " uma
ferramenta de reflexão e uma experiência vivenciada". (ANTUNES, 2003 P.55)

A partir desta discussão, reconhecendo a importância de envolver jogos didáticos nas aulas de geografia, para que haja um entendimento do aluno em sua sala de aula, a importância de aprender a cartografia geográfica. Deste modo o professor tem de agir com entretenimento e trazendo de forma diversificada sua aula sobre geografia cartográfica, dando a eles condições para aprender a como se orientar no espaço com seu próprio corpo, Castrogiovanni (2002) diz que:

Para que uma criança se oriente no espaço, é necessário que se oriente com seu próprio corpo. [...] a lateralidade consiste na representação dos hemisférios corporais e a sua consequente projeção, tendo a noção de direita, esquerda, frente, atrás, através de deslocamentos mental direto e reversíveis. (CASTROGIOVANNI, 2002 p.31) 
Entendemos que o educador trabalhando de forma criativa, consegue-se desperta o interesse e a curiosidade do aluno em querer aprender cada vez mais sobre o meio em qual está inserido, tendo prazer em aprender geografia. Atualmente o educador de geografia tem bastante dificuldade em prender a atenção do seu aluno, Abreu (2015 p.63) salienta que o professor precisa ser um bom pesquisador atento as dificuldades que se encontra em seu meio. “ $\{\ldots\}$ sem a pesquisa o trabalho docente fica fragmentado, haja vista, que é através da pesquisa, que encontramos o caminho promissor para criar uma nova postura $\{\ldots\}$ ”. Mediante a este contexto parte do educador buscar novas metodologias para inserir nas aulas de geografia.

\section{METODOLOGIA}

Para o presente trabalho optou-se por uma abordagem qualitativa pela amplitude da visão no campo investigado, permitindo captar as relações entre os sujeitos e o objeto de pesquisa. Minayo (2010, p 21) afirma que o aspecto qualitativo se evidencia no direcionamento de um estudo consistindo na apreensão do "universo dos significados, motivações, crenças, valores e atitudes, o que correspondente a um espaço mais profundo das relações, dos processos [...]".

Esta pesquisa teve como objetivo mostrar como os jogos didáticos ajudaria na compreensão do conteúdo aplicado em sala de aula. Tendo como público alvo, educandos do $7^{\circ}$ ano do ensino fundamental de uma escola Municipal do Município de Passira, agreste pernambucano. As atividades realizadas em sala foram subdivididas em etapas, a saber: no primeiro momento foi desenvolvida uma aula conceitual sobre o tema cartografia básica, de modo que houvesse compreensão, através de uma breve explicação teórica. No segundo momento, conduzimos os estudantes a organizar um círculo em sala de aula, pois apresentamos um mapa mundial onde com a interação de todos, fizemos perguntas sobre as localizações dos hemisférios e a posição do sol referente a cada continente localizado no mapa.

No terceiro momento foi desenhado no chão uma rosa dos ventos e cada aluno ficou em uma ponta representando os pontos cardeais e colaterais, se posicionando de acordo com o sol. Questionamos aos mesmos que se encontravam fora da figura ilustrativa desenhada no chão "onde o sol ilusório se posiciona nesta sala?" E eles respondiam se estava no Norte, sul, leste, oeste, nordeste e outros. Por fim, foi submetido aos alunos uma folha de papel, onde foi pedido que desenhassem a sala de aula, com o balão erguido em um ponto do ambiente, 
norteando a sala com base no ilusório do sol.

\section{RESULTADOS E DISCUSSÕES}

Despertar o interesse dos estudantes foi o que possibilitou a elaboração de atividades com reflexo direto no desempenho dos mesmo sobre o conteúdo proposto em sala de aula, com esta prática foi notável uma maior interação ente aluno e professor, possibilitando uma exploração lúdica abrangendo um leque de conhecimentos. Sabendo da fragilidade do ensino cartográfico, foi perceptível notar que uma certa parte dos alunos não compreendiam a dinâmica, visto que eles não tinham visto aquele assunto aprofundado como deveria.

DIAS (2001), afirma que os sujeitos nas maiorias das escolas recebem diretrizes, e devem aceita-las para que possam ter um padrão submetido pela própria escola. Impedindo que os professores tragam à sua sala de aula, atividades lúdicas para que haja melhor compreensão da turma. Um dos grandes problemas nas escolas nos dias de hoje é justamente esse impasse, onde os professores em alguns casos exercem a função de educador geográfico sem ao menos ser licenciado em Geografia, e este dilema afeta diretamente os estudantes, pois tem um pedaço de seu conhecimento degradado.

Título: Elaboração jogo lúdico utilizando a rosas dos ventos

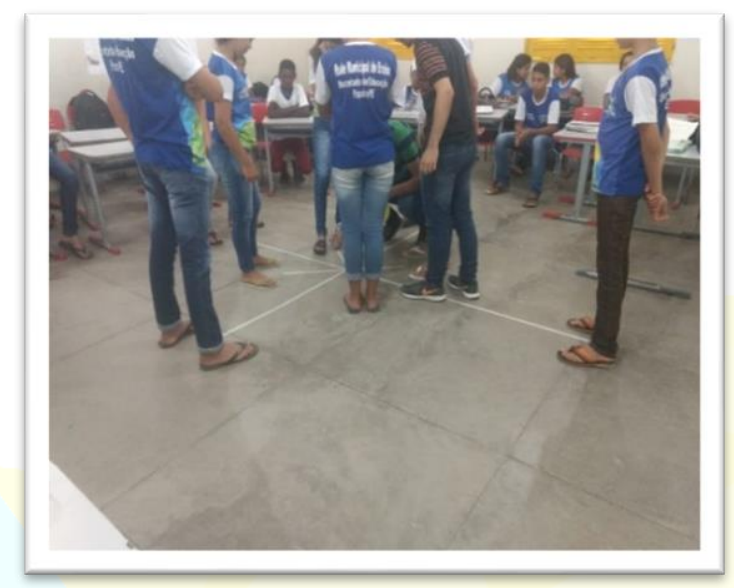

Fonte: os autores ,2018

$\mathrm{Na}$ imagem acima, apresenta-se que com atividades lúdicas à uma maior compreensão por partes dos alunos pois, a atividade propõe que durante o jogo aluno fique atento ao que está sendo demarcado, fazendo com que ele mergulhe no jogo e interaja com seus colegas. Logo vemos a importância dos jogos didáticos, pois aulas tradicionais em que os estudantes apenas copiam e ler livros não se tem o resultado esperados, já com a prática dos jogos, o rendimento tende a melhorar muito mais, visto que com a elaboração de brincadeiras lúdicas o discente consegue compreender o conteúdo de forma mais rápida. Castrogiovanni (2002), 
pontua que as relações projetivas são as que permitem a concepção do espaço em que se habita, onde possa observar o ponto de referência na própria criança, e assim será transmitido a ela uma nova forma de aprendizagem.

Título: Atividade relativa a orientação cartográfica

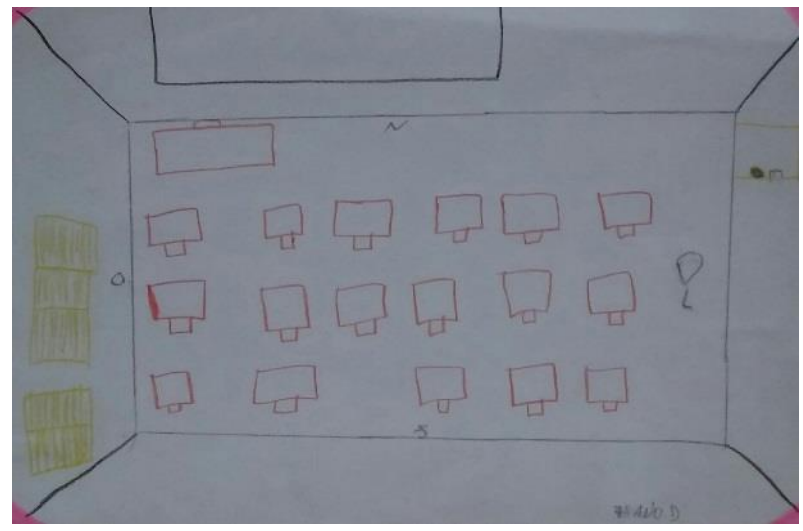

Fonte: os autores, 2018

Nesta imagem, retrata a conclusão da aula aplicada, onde os alunos deveriam se orientar através de um balão que simbolizava o sol, os estudantes ilustraram sua sala de aula em uma folha norteando ela com base no sol, ainda sem que eles percebessem estavam desenvolvendo uma forma cartográfica elaborando um mapa de seu meio, a sala de aula. Existem vários estudos relacionados à utilização de jogos nas aulas de Geografia, embora esse tipo de iniciativa ainda seja muito tímida devido, muitas vezes, ao medo de inovar e ultrapassar as barreiras burocráticas que a coordenação escolar impõem, além das dificuldades estruturais, principalmente no ensino público. No entanto, constatou-se a aceitação dos alunos por esse tipo de iniciativa e melhor rendimento no processo de ensino e aprendizagem.

\section{CONCLUSÕES}

A atividade lúdica e o jogo intervêm de maneira positiva no aprendizado em sala de aula. No processo educativo o essencial é aproveitar tudo aquilo que o aluno tem de conhecimento no seu campo cognitivo e utilizar como norte para o desenvolvimento da aprendizagem. Para que essa aprendizagem aconteça o aluno deve ter vontade em aprender, ou todo o esforço por parte do professor tornará a aprendizagem mecanizada. Buscou-se propor aos alunos, hábitos de pensar, refletir e agir criticamente através de atitudes que aumentassem o acesso ao conhecimento, ressaltando a importância de novas metodologias utilizadas pelo professor. Os objetivos iniciais foram alcançados, pois houve um envolvimento excelente dos alunos durante aula teórica e na aplicação dos jogos, obtendo ótimos resultados quanto a aprendizagem dos conteúdos propostos. 


\section{REFERÊNCIAS}

ANTUNES. C; O jogo e a educação infantil falar e dizer/ olhar e ver / escutar e ouvir: Petrópolis, RJ, editora vozes,2003. p.55

CALLAI. H. C.; KAERCHER. N. A.; Ensino de geografia/ práticas e textualizações no cotidiano. In CASTROGIOVANNI. A. C. (ORG) Apreensão e compreensão do espaço geográfico: atividade sobre lateralidade e o mapa corporal,2 ed. p.31. Porto Alegre. Editora mediação, 2002.

CASTELlAR, S.; VILHENA, J. Ensino de geografia: SÃO PAULO, Cengage learning, 2011.p.25.

DIAS, M.C.M.; metáfora e pensamento: considerações sobre a importância do jogo na aquisição do conhecimento e implicação para a educação pré-escolar. In KISHIMOTO, T.M. (org) Jogos, brinquedo, brincadeiras e a educação, 5.ed. p.54, SÃO PAULO, Cortez, 2001.

MINAYO, Maria Cecília de Souza (Org.). Pesquisa social: teoria, método e criatividade. 29. ed. Petrópolis: Vozes, 2010.

SILVA, V.; MUNIZ, A.M.V. A Geografia escolar e os recursos didáticos: o uso das maquetes no ensino-aprendizagem da Geografia. Geosaberes, Fortaleza, v. 3, n. 5, p. 62-68. Jan/jun. 2012.

SILVA. P.R.F de A.; Rumos do professor contemporâneo: A epistemologia genética e o pensamento complexo: São Caetano do sul, SP, Lura editorial, 2015. p.63.

SMOLE, Kátia; DINIZ, Maria; CÂNDIDO, Patrícia. Série Cadernos do Mathema -Ensino Fundamental. Porto Alegre: Artmed, 2007.

VIEIRA, M. M. F. e ZOUAIN, D. M. Pesquisa qualitativa em administração: teoria e prática. Rio de Janeiro: Editora FGV, 2005. 